\title{
PATIENT-IMPORTANT OUTCOMES REPORTED IN CLINICAL STUDIES OF PHARMACOLOGIC TREATMENTS FOR COVID-19: A PROTOCOL OF A META- EPIDEMIOLOGICAL STUDY
}

\author{
Authors \\ Mario A. Jimenez-Mora1 - ma.jimenez74@uniandes.edu.co \\ Andrea Ramírez Varela1 - an-rami2@uniandes.edu.co \\ Jose F. Meneses-Echavez ${ }^{2}$ - jose.meneses@fhi.no \\ Julia Bidonde ${ }^{3,4,5}$ - julia.bidonde@york.ac.uk \\ Adriana Angarita-Fonseca ${ }^{6,7}$ adriangarita@udes.edu.co \\ Reed AC Siemieniuk ${ }^{8}$ - reed.siemieniuk@medportal.ca \\ Dena Zeraatkar - zeraatd@mcmaster.ca \\ Jessica J. Bartoszko - bartosj@mcmaster.ca \\ Romina Brignardello-Petersen ${ }^{8}$ - brignarr@mcmaster.ca \\ Kimia Honarmand ${ }^{9}$ - kimia.honarmand@medportal.ca \\ Bram Rochwerg ${ }^{8,10}$ - rochwerg@mcmaster.ca \\ Gordon Guyatt ${ }^{8}$ - guyatt@mcmaster.ca \\ Juan José Yepes-Nuñez ${ }^{1,11}$ - ji.yepesn@uniandes.edu.co
}

\footnotetext{
Affiliations

${ }^{1}$ School of Medicine, Universidad de los Andes, Bogotá, Colombia

${ }^{2}$ Division for Health Services. Norwegian Institute of Public Health. Oslo, Norway.

${ }^{3}$ York Health Economic Consortium, University of York, York, UK

${ }^{4}$ Division for Health Services. Norwegian Institute of Public Health. Oslo, Norway.

${ }^{5}$ School of Rehabilitation Science, Univ of Saskatchewan, SK, Canada

${ }^{6}$ Université de Montréal, Montréal, Quebec, Canada
} 
${ }^{7}$ Universidad de Santander, Bucaramanga, Santander, Colombia

${ }^{8}$ Department of Health Research Methods, Evidence, and Impact, McMaster University, Hamilton, ON, Canada

${ }^{9}$ Division of Critical Care, Department of Medicine, Western University, London, ON, Canada

${ }^{10}$ Department of Medicine, McMaster University, Hamilton, ON, Canada

11 Pulmonology Service, Internal Medicine Section, Fundación Santa Fe de Bogotá University Hospital, Bogotá, Colombia

\section{Corresponding authors:}

Juan José Yepes-Nuñez. School of Medicine, Universidad de los Andes Bogotá, D.C., Colombia, 111711. E-mail: ji.yepesn@uniandes.edu.co

Jose F. Meneses-Echavez. Division for Health Services. Norwegian Institute of Public Health. Oslo, Norway. E-mail: jose.meneses@fhi.no 


\section{ABSTRACT}

Background: The coronavirus disease 19 (covid-19) pandemic has underscored the need to expedite clinical research, which may lead investigators to shift away from measuring patient-important outcomes (PIOs), limiting research applicability. We aim to describe the extent to which randomized controlled trials (RCTs) of covid-19 therapies will determine PIOs. Methods: We will perform a meta-epidemiological study of RCTs that included people at risk for, or with suspected, probable, or confirmed covid-19, examining any pharmacological treatment or blood product aimed at prophylaxis or treatment. We will obtain data from all RCTs identified in a recent published network metanalysis (NMA). To categorize the outcomes according to their importance to patients, we will adapt a previously defined hierarchy: a) mortality, b) quality of life/ functional status/symptoms, c) morbidity, and d) surrogate outcomes. Outcomes within the category a) and b) will be considered critically important to patients, and outcomes within the category c) will be regarded as important. We will use descriptive statistics to assess the proportion of studies that report each category of outcomes. We will perform univariable and multivariable analysis to explore associations between trial characteristics and the likelihood of reporting PIOs. Discussion: The findings from this meta-epidemiological study will help health care professionals and researchers understand if the current covid-19 trials are effectively assessing and reporting the outcomes that are important to patients. If a deficiency in capturing PIOs is identified, this information may help inform the development of future RCTs in covid-19.

\section{Open Science Framework registration: https://osf.io/6xgjz/}

Keywords: Patient-important outcome, reporting, treatment, prevention, coronavirus, covid19. 


\section{BACKGROUND}

Healthcare systems worldwide have called for the increased involvement of lay people, which has led public and patients to become more active in their own health and health care decisions. Patient-important outcomes (PIO) are gaining wide acceptance in most fields of clinical research with clinicians and researchers advocating for "the patient at the center" of medical decision making (1).

This trend has provoked a shift when recommending interventions. In the past, the magnitude of the effect as "clinically relevant" was considered as the most relevant factor; judgments have replaced this as to whether effects are it is "patient-important" (1). The notion of "patient-important" sheds light on the individual clinical encounter and the importance of patients' values and preferences. In clinical research, a PIO has been previously defined as: "a characteristic or variable that reflect how a patient feels, functions or survives" $(2,3)$.

This change in clinical decision-making paradigm represent a shift from a parental model of care in which the clinician decides the relevant outcomes to a patient-centered approach involving patients' values and preferences (1). This shift becomes especially important when one considers that, despite compelling physiological rationale, interventions' that impact on surrogate outcomes such as laboratory results often fail to achieve patient-important benefit (4).

Thus, including PIOs become of essential importance when assessing the benefits and harms of a new therapy. However, despite this potential, PIOs are often not the focus of clinical trialists. Because a focus on surrogates results in trials that are faster, cheaper, and require fewer patients, many trialists focus on endpoints that are not in themselves important 
(5). Health care providers and administrators perceive time to collect and input data as the greatest barriers to PIO implementation (6). However, given the repeated failure of intervention effects on surrogate outcomes to align with effects important to patients, the result may be implementation of useless or even harmful interventions (7).

In the coronavirus disease 19 (covid-19) pandemic, researchers are rushing to test pharmacological interventions that may decrease the personal and social burden of the disease as well as making producing associated guideline recommendations (8). The need to obtain expedient answers may lead investigators to shift away from PIOs, which can lead to unresolved questions regarding the benefits and harms of the treatments. In an effort to standardize outcome measures in covd-19 studies, the World Health Organization has developed a minimal set of common outcome measures for ongoing and future covid-19 studies (9). With hundreds of current and future covid-19 RCTs ongoing or planned, it is essential to understand the outcomes being evaluated.

\section{METHODS}

The protocol for this meta-epidemiological study is registered in Open Science Framework (OSF) (https://osf.io/6xgjz/) and the study will be conducted and reported in line with international standards $(10,11)$. For the development of the present protocol, we used to the Preferred Reporting Items for Systematic Review and Meta-Analysis Protocols (PRISMA-P) (12) (see Additional File 1). This project is associated to a recently published network metanalysis (NMA) that compared the effects of treatments for covid-19 (13).

\section{Data source and eligibility criteria}

We will obtain data from all randomized controlled trials (RCTs) identified in a recent published NMA (13) published until September 2020, that a) included people at risk for, or 
with suspected, probable, or confirmed covid-19 and b) include any pharmacological treatment or blood products intervention aimed either at prophylaxis or treatment vs placebo, standard care, an alternative intervention and/or no intervention. We will apply no restrictions based on illness severity or setting. We will include studies regardless of their publication status (peer reviewed, in press, or preprint) or language.

\section{Data extraction and coding}

We will use a standardized data extraction form to collect the data from included studies. Pairs of reviewers will extract data and classify the outcomes independently and in duplicate. Disagreements between reviewers will be resolved through discussion and consensus. If necessary, a third reviewer will be consulted.

The following details will be extracted:

- Type of publication (peer-reviewed vs. preprint)

- Patient characteristics (age, gender, disease severity, and comorbidities)

- Covid-19 diagnosis method (nucleic tests vs. clinical criteria)

- Publication characteristics (country, type of funding, trial phase, sample size, design, whether the study protocol had been previously published

- Interventions' characteristics (doses, routes and duration of administration)

- Outcomes (standard mean or standard mean difference for continuous outcomes, and odds ratio or relative risk for dichotomous outcomes).

We will extract information for all outcomes (primary and other), along with their corresponding definition. We will categorize the outcomes according to their importance to patients adopting a previously established hierarchy (14-16), which was adjusted to include, but not limited to, relevant outcomes in COVID-19, as follows: 


\begin{tabular}{|c|c|}
\hline a) Mortality & $\begin{array}{l}\text { - } \text { all-cause mortality } \\
\text { - disease-specific mortality }\end{array}$ \\
\hline $\begin{array}{l}\text { b) Quality of life / } \\
\text { Functional status / } \\
\text { Symptoms }\end{array}$ & $\begin{array}{l}\text { - } \text { mental health } \\
\text { - } \text { physical health } \\
\text { - } \text { prevalence of fever } \\
\text { - } \text { clearance time of fever } \\
\text { - clearance recovery time score of clinical symptoms } \\
\text { - } \text { pneumonia severity index }\end{array}$ \\
\hline c) Morbidity & $\begin{array}{l}\text { - respiratory support (e.g., respiratory failure occurred, need } \\
\text { for respiratory support, mechanical ventilation required, } \\
\text { duration of mechanical ventilation, frequency of } \\
\text { requirement for mechanical ventilation, ventilator free days, } \\
\text { need for non-invasive mechanical ventilation, including } \\
\text { noninvasive ventilation (NIV) and high flow nasal cannula } \\
\text { (HFNC), prevalence of mechanical ventilation) } \\
\text { cardiovascular major morbid events (e.g. stroke, } \\
\text { myocardial infarction) } \\
\text { other major morbid events (e.g., intensive care unit (ICU) } \\
\text { admission, shock occurrence, prevalence and time of } \\
\text { progressing to severe or critical types, renal replacement } \\
\text { therapy, vasopressor support) } \\
\text { incidence/prevalence of severe acute respiratory distress } \\
\text { syndrome (ARDS) coronavirus } 2 \text { disease (e.g., recovery }\end{array}$ \\
\hline
\end{tabular}




\begin{tabular}{|c|c|}
\hline & $\begin{array}{l}\text { prevalence) and other chronic diseases (e.g., COPD } \\
\text { exacerbation, new onset of diabetes) } \\
\text { - hospitalization, medical and surgical procedures (e.g., } \\
\text { length of hospital stay, time to achieve a normal respiratory } \\
\text { rate, rate of survival,) } \\
\text { - organ failure (in addition to pulmonary) } \\
\text { - adverse events or side effects (any) }\end{array}$ \\
\hline $\begin{array}{l}\text { d) Surrogate } \\
\text { outcomes }\end{array}$ & $\begin{array}{l}\text { - viral load, virus antibody level, oxygen saturation, arterial } \\
\text { blood-gas analysis, lymphocyte count, } \mathrm{PaO} 2 / \mathrm{FiO} 2 \text {, C- } \\
\text { reactive protein (CRP) level, time for } \mathrm{CRP} \text { return to } \\
\text { baseline, time to negative conversion of severe acute } \\
\text { respiratory syndrome coronavirus } 2 \text {, lesions progression } \\
\text { within } 24-48 \mathrm{~h} \text { in pulmonary imaging }\end{array}$ \\
\hline
\end{tabular}

Outcomes within the category a) and b) will be considered critically important to patients, and outcomes within the category c) will be regarded as important (14). Outcomes within category d) will be regarded as not patient-important. We will identify the "most patientimportant outcome" of each study as the outcome that pertains to the highest level of the hierarchy (16). For the primary outcome (as reported by the authors) and the most patientimportant outcome, we will determine if it is one of benefit or harm and will extract the relative and the absolute effect estimates used to report the outcome results. Data of the risk of bias assessment will be also obtained from the original NMA (13).

\section{Data synthesis}

We will use descriptive statistics to summarize the study characteristics. We will use frequencies and percentages to describe the proportion of studies that report: 
- Each individual outcome in each study.

- Each outcome category (a to d).

- A PIO (category a or b or c) as the primary outcome of the study.

- The most PIO as the primary outcome of the study.

Bivariate analyses (odds ratios and their associated 95\% confidence intervals) will be performed to explore associations between trial characteristics and likelihood of reporting PIOs. To test possible predictors, we will perform multivariable analyses, using logistic regression, with $\mathrm{PIO}$ (yes/no) reported as the dependent variable where it will positive if a trial included PIOs as the primary outcome in its report. We plan to conduct more than one multivariable analysis because the dependent variable can be different according to the most patient important outcome (category $\mathrm{a}$ or $\mathrm{b}$ or $\mathrm{c}$ ). The independent predictors will include: 1) type of funding (industry supported vs non-industry supported); 2) number of patients (every additional 100 patients); 3) severity of disease (mild/moderate or mixed vs severe, in not prophylactic RCTs); 4) follow-up duration (for every additional 30 days); 5) type of publication (regular vs. preprint); 6) risk of bias (high vs low); 7) prophylaxis trials vs treatment trials; and 8) pharmacological interventions vs blood products. The rationale for choosing these predictors is 1) patient-important outcome reporting may be more frequent in non-industry supported studies; 2) smaller trials may be less likely to report patientimportant outcomes because they are not powered for these outcomes; 3) trials enrolling patients with severe disease, may be more likely to report patient-important outcomes; 4) trials with shorter follow- up duration may be less likely to report patient-important outcomes because mortality and morbidity events possibly require longer time to occur; 5) publication in an indexed journal after peer review are expected to report more patient-important outcomes; 6) studies that report patient-important outcome may display an overall lower risk of bias; 7) prophylaxis trials may be less likely to report patient-important outcomes; and 8) pharmacological intervention trials may be more likely to report patient-important outcomes. 
We will classify the studies as high or low risk of bias using the same threshold reported by Siemieniuk et al (13). A study will be classified with an overall high risk of bias if one or more domains were rated as some concerns- probably high risk of bias- or as high risk of bias; and as overall low risk of bias if all domains were rated as some concerns-probably low risk of bias- or low risk of bias. This systematic review is nested in a previously published NMA, which will be updated. According to Peduzzi et al. (17)., the minimum required sample size should be based on the rule of 10 event per independent variable. Since in the published NMA, 39 out of 41 trials evaluated PIOs and the planned number of predictors is 8 , we will include all trials that meet the inclusion and exclusion criteria. We estimated that we need at least 80 trials that measured PIOs. However, we need to add 5\% $(n=4)$ trials that will not evaluate a PIO and $20 \%(n=16)$ that will not evaluate the 8 predictors at the same time. This meant that we need to include 100 trials. Considering that trials are usually unpowered to detect predetermined significant differences in their primary outcomes, we considered primary outcomes in our main analysis and conducted sensitivity analysis using both primary and secondary outcomes.

\section{DISCUSSION}

To our knowledge, this protocol describes the first meta-epidemiological study that specifically examines the frequency of PIOs reporting in RCTs in covid-19. Previous studies have described the frequency of PIOs in systematic reviews that included RCTs in diabetes (5) and critically ill patients (18). Umbrella reviews have also explored the frequency of PIOs included in systematic reviews of therapeutic interventions for different conditions (19), in the full texts and abstracts of Cochrane and non-Cochrane reviews (14), and in a systematic review that explored whether the outcomes reported in the summary of finding tables (SoF) of Cochrane systematic reviews included PIOs (20). 
This meta-epidemiological study will describe the proportion of studies that reported individual outcomes and their categories, or patient-important outcome as the primary outcome of the study, and the most patient-important outcome as the primary outcome of the study.

Our target users are health care professionals, as well as researchers, decision makers and other stakeholders. We plan to present our results at national and international meetings. Limitations to the meta-epidemiological study may include the diversity of outcomes from different clinical trials that may limit our capacity to classify these outcomes in our proposed category.

The findings from this meta-epidemiological study will help health care professionals and researchers understand if the current COVID-19 trials are effectively assessing and reporting the outcomes that are actually relevant to patients. This study will also identify gaps in outcomes reporting which might be useful for further research and priority setting and it will support decision making and the planning of future clinical trials.

\section{LIST OF ABBREVIATIONS}

ARDS = Acute respiratory distress syndrome

Covid-19= Coronavirus disease 2019

COPD $=$ Chronic obstructive pulmonary disease

$\mathrm{CRP}=\mathrm{C}$-reactive protein

$\mathrm{ICU}=$ Intensive care unit

NMA= network metanalysis

NIV= noninvasive ventilation

HFNC= high flow nasal cannula

$\mathrm{PaO} 2 / \mathrm{FiO} 2=$ ratio of arterial oxygen partial pressure to fractional inspired oxygen

$\mathrm{PIO}=$ Patient-important outcome 
RCT= Randomized Clinical Trials

\section{DECLARATIONS}

Ethics approval and consent to participate

Not applicable.

\section{Consent for publication}

Not applicable.

\section{Availability of data and materials}

The datasets created and analyzed during this survey will be available from the corresponding author upon reasonable request.

\section{Competing interests}

The authors declare no competing interests.

\section{Funding}

The authors received no specific funding for this work.

\section{Authors' contributions}

JJY-N conceptualized the study. JJY-N, MAJ-M, JFM-E, JB, and ARV designed this protocol and drafted the article. All authors actively reviewed this manuscript and provided substantial feedback. All authors read and approved the final version of the manuscript. JJY-N is the guarantor of the review.

\section{REFERENCES}

1. Guyatt G, Montori V, Devereaux PJ, Schunemann H, Bhandari M. Patients at the center: in our practice, and in our use of language. ACP J Club. 2004;140(1):A11-2.

2. Wittes J, Lakatos E, Probstfield J. Surrogate endpoints in clinical trials: cardiovascular diseases. Stat Med. 1989;8(4):415-25. 
3. Pino C, Boutron I, Ravaud $\mathrm{P}$. Outcomes in registered, ongoing randomized controlled trials of patient education. PLoS One. 2012;7(8):e42934.

4. Rossouw JE, Anderson GL, Prentice RL, LaCroix AZ, Kooperberg C, Stefanick ML, et al. Risks and benefits of estrogen plus progestin in healthy postmenopausal women: principal results From the Women's Health Initiative randomized controlled trial. JAMA. 2002;288(3):321-33.

5. Gandhi GY, Murad MH, Fujiyoshi A, Mullan RJ, Flynn DN, Elamin MB, et al. Patientimportant outcomes in registered diabetes trials. JAMA. 2008;299(21):2543-9.

6. Philpot LM, Barnes SA, Brown RM, Austin JA, James CS, Stanford RH, et al. Barriers and Benefits to the Use of Patient-Reported Outcome Measures in Routine Clinical Care: A Qualitative Study. Am J Med Qual. 2018;33(4):359-64.

7. Bucher HC, Guyatt GH, Cook DJ, Holbrook A, McAlister FA. Users' guides to the medical literature: XIX. Applying clinical trial results. A. How to use an article measuring the effect of an intervention on surrogate end points. Evidence-Based Medicine Working Group. JAMA. 1999;282(8):771-8.

8. Schunemann HJ, Santesso N, Vist GE, Cuello C, Lotfi T, Flottorp S, et al. Using GRADE in situations of emergencies and urgencies: certainty in evidence and recommendations matters during the COVID-19 pandemic, now more than ever and no matter what. J Clin Epidemiol. 2020.

9. Characterisation WHOWGotC, Management of C-i. A minimal common outcome measure set for COVID-19 clinical research. Lancet Infect Dis. 2020;20(8):e192-e7.

10. Higgins JPT, Thomas J, Chandler J, Cumpston M, Li T, Page MJ, Welch VA (editors). Cochrane Handbook for Systematic Reviews of Interventions version 6.0 (updated July 2019). Cochrane, 2019. Available from www.training.cochrane.org/handbook.

11. Murad MH, Wang Z. Guidelines for reporting meta-epidemiological methodology research. Evid Based Med. 2017;22(4):139-42. 
12. Shamseer L, Moher D, Clarke M, Ghersi D, Liberati A, Petticrew M, et al. Preferred reporting items for systematic review and meta-analysis protocols (PRISMA-P) 2015: elaboration and explanation. BMJ. 2015;350:g7647.

13. Siemieniuk RA, Bartoszko JJ, Ge L, Zeraatkar D, Izcovich A, Pardo-Hernandez H, et al. Drug treatments for covid-19: living systematic review and network meta-analysis. BMJ. 2020;370:m2980.

14. Agarwal A, Johnston BC, Vernooij RW, Carrasco-Labra A, Brignardello-Petersen R, Neumann I, et al. Authors seldom report the most patient-important outcomes and absolute effect measures in systematic review abstracts. J Clin Epidemiol. 2017;81:3-12.

15. Akl EA, Briel M, You JJ, Lamontagne F, Gangji A, Cukierman-Yaffe T, et al. LOST to follow-up Information in Trials (LOST-IT): a protocol on the potential impact. Trials. 2009;10:40.

16. Alonso-Coello P, Carrasco-Labra A, Brignardello-Petersen R, Neumann I, Akl EA, Vernooij RW, et al. Systematic reviews experience major limitations in reporting absolute effects. J Clin Epidemiol. 2016;72:16-26.

17. Peduzzi P, Concato J, Kemper E, Holford TR, Feinstein AR. A simulation study of the number of events per variable in logistic regression analysis. J Clin Epidemiol. $1996 ; 49(12): 1373-9$.

18. Gaudry S, Messika J, Ricard JD, Guillo S, Pasquet B, Dubief E, et al. Patientimportant outcomes in randomized controlled trials in critically ill patients: a systematic review. Ann Intensive Care. 2017;7(1):28.

19. Ameur H, Ravaud P, Fayard F, Riveros C, Dechartres A. Systematic reviews of therapeutic interventions frequently consider patient-important outcomes. J Clin Epidemiol. $2017 ; 84: 70-7$.

20. Yordanov Y, Dechartres A, Ravaud P. Patient-important outcomes in systematic reviews: Poor quality of evidence. PLoS One. 2018;13(4):e0195460. 
Additional File 1. PRISMA-P Checklist.

\begin{tabular}{|c|c|c|c|c|c|}
\hline \multirow[t]{2}{*}{ Section/topic } & \multirow[t]{2}{*}{$\#$} & \multirow[t]{2}{*}{ Checklist item } & \multicolumn{2}{|c|}{$\begin{array}{l}\text { Information } \\
\text { reported }\end{array}$} & \multirow{2}{*}{$\begin{array}{l}\text { Line } \\
\text { number(s) }\end{array}$} \\
\hline & & & Yes & No & \\
\hline \multicolumn{6}{|c|}{ ADMINISTRATIVE INFORMATION } \\
\hline \multicolumn{6}{|l|}{ Title } \\
\hline Identification & $1 \mathrm{a}$ & Identify the report as a protocol of a systematic review & & & 1 \\
\hline Update & $1 b$ & $\begin{array}{l}\text { If the protocol is for an update of a previous systematic review, identify as } \\
\text { such }\end{array}$ & & & NA \\
\hline Registration & 2 & $\begin{array}{l}\text { If registered, provide the name of the registry (e.g., PROSPERO) and } \\
\text { registration number in the Abstract }\end{array}$ & $\bigotimes$ & & 3 \\
\hline \multicolumn{6}{|l|}{ Authors } \\
\hline Contact & $3 a$ & $\begin{array}{l}\text { Provide name, institutional affiliation, and e-mail address of all protocol } \\
\text { authors; provide physical mailing address of corresponding author }\end{array}$ & $\bigotimes$ & & 1,2 \\
\hline Contributions & $3 b$ & $\begin{array}{l}\text { Describe contributions of protocol authors and identify the guarantor of the } \\
\text { review }\end{array}$ & & & 13 \\
\hline Amendments & 4 & $\begin{array}{l}\text { If the protocol represents an amendment of a previously completed or } \\
\text { published protocol, identify as such and list changes; otherwise, state plan for } \\
\text { documenting important protocol amendments }\end{array}$ & & & NA \\
\hline \multicolumn{6}{|l|}{ Support } \\
\hline Sources & $5 a$ & Indicate sources of financial or other support for the review & $\bigotimes$ & & 13 \\
\hline Sponsor & $5 b$ & Provide name for the review funder and/or sponsor & & $\bigotimes$ & NA \\
\hline $\begin{array}{c}\text { Role of } \\
\text { sponsor/funder }\end{array}$ & $5 c$ & $\begin{array}{l}\text { Describe roles of funder(s), sponsor(s), and/or institution(s), if any, in } \\
\text { developing the protocol }\end{array}$ & & $\bigotimes$ & NA \\
\hline \multicolumn{6}{|l|}{ INTRODUCTION } \\
\hline Rationale & 6 & Describe the rationale for the review in the context of what is already known & $\bigotimes$ & & 5,6 \\
\hline
\end{tabular}




\begin{tabular}{|c|c|c|c|c|c|}
\hline \multirow[t]{2}{*}{ Section/topic } & \multirow[t]{2}{*}{$\#$} & \multirow[t]{2}{*}{ Checklist item } & \multicolumn{2}{|c|}{$\begin{array}{l}\text { Information } \\
\text { reported }\end{array}$} & \multirow{2}{*}{$\begin{array}{l}\text { Line } \\
\text { number(s) }\end{array}$} \\
\hline & & & Yes & No & \\
\hline Objectives & 7 & $\begin{array}{l}\text { Provide an explicit statement of the question(s) the review will address with } \\
\text { reference to participants, interventions, comparators, and outcomes (PICO) }\end{array}$ & & & 5,6 \\
\hline \multicolumn{6}{|l|}{ METHODS } \\
\hline Eligibility criteria & 8 & $\begin{array}{l}\text { Specify the study characteristics (e.g., PICO, study design, setting, time } \\
\text { frame) and report characteristics (e.g., years considered, language, } \\
\text { publication status) to be used as criteria for eligibility for the review }\end{array}$ & $\bar{\Delta}$ & & 6 \\
\hline Information sources & 9 & $\begin{array}{l}\text { Describe all intended information sources (e.g., electronic databases, contact } \\
\text { with study authors, trial registers, or other grey literature sources) with } \\
\text { planned dates of coverage }\end{array}$ & & & 6 \\
\hline Search strategy & 10 & $\begin{array}{l}\text { Present draft of search strategy to be used for at least one electronic } \\
\text { database, including planned limits, such that it could be repeated }\end{array}$ & & $\triangle$ & NA \\
\hline \multicolumn{6}{|l|}{ STUDY RECORDS } \\
\hline $\begin{array}{c}\text { Data } \\
\text { management }\end{array}$ & $11 a$ & $\begin{array}{l}\text { Describe the mechanism(s) that will be used to manage records and data } \\
\text { throughout the review }\end{array}$ & $\bigotimes$ & & 7 \\
\hline Selection process & $11 b$ & $\begin{array}{l}\text { State the process that will be used for selecting studies (e.g., two } \\
\text { independent reviewers) through each phase of the review (i.e., screening, } \\
\text { eligibility, and inclusion in meta-analysis) }\end{array}$ & & $\bigotimes$ & NA \\
\hline $\begin{array}{l}\text { Data collection } \\
\text { process }\end{array}$ & $11 \mathrm{c}$ & $\begin{array}{l}\text { Describe planned method of extracting data from reports (e.g., piloting forms, } \\
\text { done independently, in duplicate), any processes for obtaining and confirming } \\
\text { data from investigators }\end{array}$ & $\bigotimes$ & & 8,9 \\
\hline Data items & 12 & $\begin{array}{l}\text { List and define all variables for which data will be sought (e.g., PICO items, } \\
\text { funding sources), any pre-planned data assumptions and simplifications }\end{array}$ & $\bigotimes$ & & 8,9 \\
\hline $\begin{array}{l}\text { Outcomes and } \\
\text { prioritization }\end{array}$ & 13 & $\begin{array}{l}\text { List and define all outcomes for which data will be sought, including } \\
\text { prioritization of main and additional outcomes, with rationale }\end{array}$ & $\bigotimes$ & & 8,9 \\
\hline $\begin{array}{l}\text { Risk of bias in } \\
\text { individual studies }\end{array}$ & 14 & $\begin{array}{l}\text { Describe anticipated methods for assessing risk of bias of individual studies, } \\
\text { including whether this will be done at the outcome or study level, or both; } \\
\text { state how this information will be used in data synthesis }\end{array}$ & & $\bigotimes$ & NA \\
\hline
\end{tabular}




\begin{tabular}{|c|c|c|c|c|c|}
\hline \multirow[t]{2}{*}{ Section/topic } & \multirow[t]{2}{*}{ \# } & \multirow[t]{2}{*}{ Checklist item } & \multicolumn{2}{|c|}{$\begin{array}{l}\text { Information } \\
\text { reported }\end{array}$} & \multirow{2}{*}{$\begin{array}{l}\text { Line } \\
\text { number(s }\end{array}$} \\
\hline & & & Yes & No & \\
\hline \multicolumn{6}{|l|}{ DATA } \\
\hline \multirow{4}{*}{ Synthesis } & $15 a$ & Describe criteria under which study data will be quantitatively synthesized & $\bigotimes$ & & 9 \\
\hline & $15 b$ & $\begin{array}{l}\text { If data are appropriate for quantitative synthesis, describe planned summary } \\
\text { measures, methods of handling data, and methods of combining data from } \\
\text { studies, including any planned exploration of consistency (e.g., } I^{2}, \text { Kendall's } \\
\text { tau) }\end{array}$ & & $\bigotimes$ & NA \\
\hline & $15 c$ & $\begin{array}{l}\text { Describe any proposed additional analyses (e.g., sensitivity or subgroup } \\
\text { analyses, meta-regression) }\end{array}$ & $\bigotimes$ & {[} & 10,11 \\
\hline & $15 d$ & $\begin{array}{l}\text { If quantitative synthesis is not appropriate, describe the type of summary } \\
\text { planned }\end{array}$ & $\bigotimes$ & 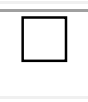 & 11 \\
\hline Meta-bias(es) & 16 & $\begin{array}{l}\text { Specify any planned assessment of meta-bias(es) (e.g., publication bias } \\
\text { across studies, selective reporting within studies) }\end{array}$ & & $\bigotimes$ & NA \\
\hline $\begin{array}{l}\text { Confidence in } \\
\text { cumulative evidence }\end{array}$ & 17 & $\begin{array}{l}\text { Describe how the strength of the body of evidence will be assessed (e.g., } \\
\text { GRADE) }\end{array}$ & L & $\bigotimes$ & NA \\
\hline
\end{tabular}

